\title{
Assessing KM Capabilities in two African Healthcare Organizations: Case Study
}

\author{
Jean-Pierre Booto Ekionea ${ }^{1,2}$ and Gérard Fillion ${ }^{1}$ \\ ${ }^{1}$ University of Moncton, Moncton, New Brunswick, Canada \\ ${ }^{2}$ Associate Professor of MIS at Institut Supérieur de Commerce de Kinshasa (ISC/Kinshasa), DR \\ Congo \\ Jean-pierre.booto.ekionea@umoncton.ca \\ Gerard.fillion@umoncton.ca
}

\begin{abstract}
This study aims to better understand the process for the development of organizational capabilities specific to knowledge management (KMC) in the context of healthcare organizations. This process lies within the framework of apprenticeship training that promotes a process for organizational training and knowledge acquisition that can be spread over time and at different levels of intellectual development. Healthcare organizations are among those organizations that still struggle to adequately use the existing knowledge of their employees, due to the lack of good knowledge management. Although most of them are modernizing with computers and new technologies, is there effective knowledge management of employees, and what is their level of KMC? Besides, massive data and information is collected every day in health facilities, do they use it for effective decision-making and to strengthen their knowledge? This paper presents an analysis and develops a model that presents five levels of intellectual progress using the KMC maturity model as a development model to assess the KMC levels of two hospital organizations in the Democratic Republic of Congo which is one of the countries of sub-Saharan Africa. Our model includes three dimensions: 1. knowledge infrastructures in knowledge management; 2) knowledge management process; 3) knowledge management competency. These three dimensions aim to seek improvements or to develop the KMC of our studied health facilities. Finally, we wish to emphasize that the conclusions of this study are not representative of quantitative research but rather qualitative research that aims to comprehend the phenomenon of the knowledge management capabilities (KMC) in a context through this case study. From a practical point of view, this article provides for the identification of factors that influence the nature and effectiveness of the use of KMC in healthcare facilities. Also, promote the use of the KMC maturity model as a model for evaluating health organizations aimed at helping the health sector to set new standards for information flow and to manage their KM well. This paper presents an analysis and develops a model of the factors that influence unlearning focused on the healthcare industry. It is comprised of three constituent components: 1) a framework characterizing the lens through which individuals view situations; 2) a framework for characterizing how individual habits change and 3) a framework for characterizing the manner in which emergent understandings are consolidated into existing knowledge and knowledge structures. This paper presents an analysis and develops a model of the factors that influence unlearning focused on the healthcare industry. It is comprised of three constituent components: 1) a framework characterizing the lens through which individuals view situations; 2) a framework for characterizing how individual habits change and 3) a framework for characterizing the manner in which emergent understandings are consolidated into existing knowledge and knowledge structures. This paper presents an analysis and develops a model of the factors that influence unlearning focused on the healthcare industry. It is comprised of three constituent components: 1) a framework characterizing the lens through which individuals view situations; 2) a framework for characterizing how individual habits change and 3) a framework for characterizing the manner in which emergent understandings are consolidated into existing knowledge and knowledge structures. This paper presents an analysis and develops a model of the factors that influence unlearning focused on the healthcare industry. It is comprised of three constituent components: 1) a framework characterizing the lens through which individuals view situations; 2) a framework for characterizing how individual habits change and 3) a framework for characterizing the manner in which emergent understandings are consolidated into existing knowledge and knowledge structures.
\end{abstract}

Keywords: Case study, knowledge management, organizational capabilities, intellectual development

\section{Introduction}

Most managers and decision-makers have taken note of the crucial role that good knowledge management can impart to their organizations. Because they are bombarded every day with information such as emails, vocal messages, faxes, reports, memos, etc. in such a repetitive fashion, they have found in knowledge management a solution to the massive input overload that they have been subjected to (Sharma, Wickramasinghe and Gupta, 2005). In effect, professionals spend most of their time searching for information they need on the Web, sending emails, making telephone calls, and examining reports both on computers and on paper (Sharma, Wickramasinghe and Gupta, 2005). The stated problem is again just as severe at the level of healthcare organizations that are preoccupied with good knowledge management to organize and to facilitate 
the conservation, circulation, and utilization of data, information, and medical knowledge as well as health administration. Furthermore, some studies (Pauker et al, 1976) prove that doctors use approximately two million pieces of information to manage their patients. Also, one-third of a doctor's time is spent on recording and combining information. Finally, one-third of the costs of health care providers are related directly to personal and professional communications (Hersch and Lunin, 1995).

Furthermore, today it is difficult and even inconceivable for a healthcare professional to properly conduct his practice without regularly upgrading his skills or exchanging information from within or outside his practice (Desouza, 2005). In effect, most healthcare organizations cannot adequately utilize the existing knowledge of their employees because of faulty documentation, a lack of sharing of expertise among employees, the turnover rate of personnel, and a lack of time and interest by employees themselves, etc (Chase, 1998). Besides, this problem is serious in African organizations in general and in particular in the healthcare organization of the Democratic Republic of Congo, as many of them have not yet implemented information technology and are using more handwriting data that leads to management and decision making not based on fact or information extracted (Mbeva et al, 2014). Therefore, obtaining knowledge or information is a major preoccupation of healthcare organizations, both hospitals, and clinics. For, until now, in North America, Europe, and developing countries, most of the information and the knowledge base on patients are still retained on paper reports or cards. In addition, the information and the knowledge base are distributed throughout the hospital without order or structure (Desouza, 2005). It is therefore increasingly evident that the development of organizational capabilities of capture, transfer, and the dissimilation of data, as well as medical knowledge and information throughout an organization, is one of the critical factors in almost all business disciplines (Earl, 2001). Hence, the development of KM capabilities (KMC) occurs through the development and utilization of specific maturity models ( Ehms and Langen, 2001; Klimko, 2001; Kaner and Karni, 2004; Harigopal and Satyadas, 2001; Dayan and Stephen, 2006; Berztiss, 2002; Johnson and Brodman, 2002).

Thus, the evaluation of capabilities to capture, transfer, and dissimilate data, information, and medical knowledge of a healthcare facility based on a maturity model is indispensable. In effect, many reasons argue in favour of knowledge management within healthcare organizations, particularly (Wahle and Groothuis, 2005): 1- Hospitals and all other healthcare organizations are the central nexus for exchanging detailed knowledge and information; 2- There is an increased demand to optimize support for basic medical procedures; 3- There is a need for efficiency and effectiveness in dispensing health care; 4- Patients are increasingly more demanding regarding the quality of healthcare they receive along with medical information on their illness; 5There is a need to exchange data, information, and knowledge between different providers (professionals and organizations); 6- An increasing number of autonomous professional disciplines intervene thus interact with the patient and need to conserve, exchange, and utilize the knowledge of the speciality in order to improve their knowledge base and their operational effectiveness; 7- Certain unique knowledge that emerges at times during the interaction of the patient-doctor relationship needs to be captured, secured, shared, and utilized.

Hence, throughout the present study, the KMC of the two healthcare organizations are evaluated as per the KMC maturity model (KMCMM) that is an integral model consisting of five (5) levels and comprising three (3) dimensions: knowledge management infrastructures, knowledge management processes, and knowledge management competency (Booto Ekionea and Abou-Zeid, 2005). This evaluation will allow us to identify the maturity level for each dimension and sub-dimension of each facility studied to seek improvements or develop the KMC. In effect, the organizations require solid avenues that can support them in the capture, conservation, transformation, sharing, and application of knowledge based on previous experiences and new methods learned in order to respond to present and future needs (Rubenstein and Geisler, 2005, p. 45).

Thus, apart from the introduction and the conclusion, the present article is subdivided into four (4) sections: 1 - Review of literature where the concepts of data, information, and knowledge are defined in the clinical and hospital contexts as well as the concepts of KMC and the maturity models; 2 - The design of the case study where we present the methodology used, as inspired by Yin (1994); 3 - The results of the case study where we present the evaluations of the KMC obtained in each facility studied with individual and consolidated results and where an inter-caste analysis is presented i.e. a transversal analysis according to the deductive method that places the accent on the importance of validating the data with the theoretical model (the KMCMM); $4-$ Discussions and perspectives on the concepts of the KMC where the diagnostics, the causes, and the 
challenges yet to overcome by healthcare organizations are presented and the perspectives for research on the academic level.

\section{Literature Review}

From a theoretical viewpoint, the present study relies on six (6) axioms: Axiom 1: Knowledge is a strategic organizational resource and likely to provide a competitive advantage and to help attain business performance objectives. Thus medical knowledge can be considered as being an ensemble of personal information versus non-personal information relative to administrative information " administrative file ", medical information " medical dossier ", recorded information of all events related to the patient, and the " nursing file " from which treatment is conducted, to results of epidemiological studies, to knowledge on the proper channels to maintain (therapeutic protocols, guides to proper practices), to thesaurus consultations, as well as information that is organized according to the aims of the healthcare establishment (Beveren, 2003). Weixu, Eugene and Atsuhi (2019), argue that « In the increasingly fierce competitive market environment, researchers believe that knowledge is an important organizational resource, and knowledge administration is deemed to enhance firms' competitive capability». Axiom 2: Organizational knowledge management is a difficult task that requires the development of specific organizational capabilities without which the acquiring of competitive advantage and business performance is impossible (Peppard and Ward, 2004; St-Amant and Renard, 2004). In effect, knowledge management is very important particularly in the healthcare sector because of the continuous data flux, information, and knowledge in circulation. A healthcare establishment is comprised of numerous professional specialists that contribute to the healthcare accorded to patients (Beveren, 2003). Therefore, this establishment should develop capabilities to create, diffuse or share the knowledge across the establishment to improve the healthcare accorded to patients (Beveren, 2003); Axiom 3: The development of organizational capabilities specific to knowledge management $(K M C)$ is defined along three dimensions: KM infrastructures, KM processes, and KM competencies (Abou-Zeid, 2003; Ahn and Chang, 2005); Axiom 4: Observing the efforts or initiatives of developing or improving KMC derives from a learning curve and can only be done through a specific maturity model (Préfontaine, 1994; Peppart and Ward, 2004; Luftman et al, 2004; Dekleva and Drehmer, 2001; Venkatraman, 1994; St-Amant and Renard, 2004). In effect, the maturity model evaluates the level of success of one or more general objectives using a scale of 0 to 5 as follows: 0 : non-existing; 1 : existing but not organized (initiated case by case), 2: practiced (intuitive but reproducible), 3: defined (with documentation), 4: supervised and measured, 5: optimized. The current paper considers a scale of maturity levels from 1 to 5 for each dimension and characteristic of the KMC; Axiom 5: The maturity model expresses the level of performance that an establishment can achieve as a function of the level of development of the KMC; Axiom 6: The validity of this model in a context particular to the healthcare organizations studied will help to better understand the inclusion of maturity models as a diagnostic tool of KMC, and in the development processes of KMC within an establishment.

\section{The importance of good management of data, information, and medical knowledge}

Information of raw data is subject to interpretation by computers or human mental functions (Spiegler, 2000). Consequently, knowledge is a combination of information or observation, their inherent interpretation by people who summon their personal or collective experience, along with models, theories, or beliefs that together give meaning to the information (Prax, 2003). The concept of knowledge, therefore, relies on the range of senses, notable notions such as language, semantics, beliefs, and conscience. In effect, we acknowledge that factual information can be easily accumulated and transferred to documents or databases in explicit form, while knowledge, in a strict sense, is an element more humane, subjective, and often tacit. Hence, Nonaka (1994) distinguishes two types of knowledge: tacit and explicit.

Tacit knowledge belongs to the knowledge group of mental objects or representations. It encompasses innate or acquired knowledge, expertise, and experience. They are generally difficult to " formalize » as opposed to explicit knowledge (Nonaka, 1994). Explicit knowledge, contrary to tacit knowledge, is the knowledge that is clearly articulated in written documents or found in IT or computer data systems. This knowledge is physically transferable since it appears in tangible form (paper or electronic data) (Nonaka, 1994). Certain other knowledge-based information is dissimilated throughout the company in support of paper forms and electronic data. This knowledge must be managed to improve the global effectiveness and competitiveness of companies (Wernerfelt, 1984; Barney, 1991). 
Therefore, knowledge management or knowledge engineering in this paper is understood to be the sum of all the methods and techniques that allow us to perceive, identify, analyze, organize, memorize, and share knowledge between members of organizations, particularly knowledge created by the company itself or acquired from outside.

However, knowledge management differs from one organization to another, from one industry to another, and from one contextual reality to another, hence the need to contextualize the approaches to knowledge management. In effect, the contextualizing of knowledge in philosophy is the theory according to which the attributions of knowledge can change the value of truth in the context of one conversation to another. To contextualize, one compares the word "knowledge" with other words similar in context, for example, those that change the value from one contextual conversation to another (Lewis, 1995).

Therefore, in the field of healthcare in general, especially in hospitals and in clinical settings, knowledge management is very important because of significant fluctuations of data, information, and knowledge that continuously circulate. Note that healthcare organizations are comprised of professionals in different specialties that contribute to the health and well-being of patients (Beveren, 2003). It is for this reason that such organizations should develop the capabilities to create, dissimilate or share knowledge across the entire organization in order to improve the healthcare accorded to patients (Beveren, 2003). The healthcare organizations that manage and share their combined knowledge could effectively obtain a reduction in treatment time, a reduction in costs, a return on investment, a high level of satisfaction, and sound training of medical and paramedical staff (Sharma, Wickramasinghe and Gupta, 2005: Antrobus, 1997). In addition, the medical field is faced with stringent requirements of quality and optimization of care that necessitates the management of medical knowledge. Healthcare professionals must be able to share and apply common knowledge therefore collectively valid, especially healthcare protocols that develop in numerous disciplines and presented in guidelines for sound practice, as part of the medical field that is the most protocol conscious. They must also acquire knowledge and medical expertise that will allow them to use such acquired clinical skills with their patients thus instantly applying, to the best of their abilities, general knowledge always in context with the patient before them.

In the same way, as knowledge must be shared, the responsibilities and the decisions on the type of care to be provided to patients should also be facilitated and shared within the healthcare establishment (Eisenberg, 2002). In order to do this, these organizations must develop the means to harness the knowledge and medical expertise, the protocols, sound practice guides, referenced bibliographies on medical facts and practices that are easily accessible, and facilitate their distribution in real-time throughout the establishment, etc. Thus, medical knowledge can be considered as being the sum of personal information versus non-personal information with regards to administrative information "administrative dossiers", medical information " medical dossiers", recording all events related to the patient, and the "nursing dossiers " allowing to initiate treatment, to results of epidemiological studies, knowledge on pertinent channels to retain (therapeutic protocols, sound practice guides), to a thesaurus as well as to information organized according to the aims of the healthcare establishment.

In effect, with regards to healthcare organizations, they must obtain and analyze clinical data as well as data taken from outside sources in order to visualize and organize the data into information useful for decision making (Pavia, 2001). Healthcare organizations should make available pertinent information and knowledge to consumers, patients, clinical workers, managers, directors, and other personnel (Beveren, 2003). This method of openness would help follow-ups and maintain competition between healthcare organizations that often evolve in complex and sterile environments. In effect, knowledge management in the healthcare sector implies 1 - Computerized data on patients; 2 - Telemedicine; 3 - Optimized usage and management of equipment (Rubenstein and Geisler, 2005).

Considering the preceding literature, it is easy to understand that initiatives in knowledge management bring value. However, there are major obstacles to overcome in terms of the development of specific capabilities.

\subsection{Organizational capabilities specific to knowledge management}

As markets become more complex and unpredictable, the ability of organizations to improve their performance increasingly depends on their competence to acquire and develop knowledge. Therefore, knowledge is considered the most important asset and is more important than other types of inputs or resources. In addition, knowledge-intensive organizations tend to strongly support knowledge creation 
(Sonienwicki and Paliszkiewicz, 2019). In effect, healthcare organizations need to capture, retain, transform, store, and apply the knowledge gained from previous experience and learning in order to meet their present and future needs (Rubenstein and Geisler, 2005). To achieve this, organizations must develop organizational capabilities specific to knowledge management. This would therefore justify the pertinent inclusion of the application of a specific maturity model. This model, which integrates three dimensions, will help prepare a diagnostic of the organizational capabilities specific to knowledge management which the establishment needs to better utilize its organizational knowledge. To achieve this, the present research is designed by considering the following: 1 - Knowledge is a strategic organizational resource likely to provide a competitive advantage and to help in reaching business performance levels; 2- Organizational knowledge management is a difficult task that requires the development of specific organizational capabilities without which the goal of providing a competitive advantage along with business performance is impossible (Peppard and Ward, 2004; St-Amant and Renard, 2004); 3 - The development of organizational capabilities specific to knowledge management is defined according to three dimensions: knowledge management infrastructures, knowledge management processes, and knowledge management competencies (Abou-Zeid, 2003; Chang and Ahn, 2005).

\subsection{Knowledge management infrastructure as a specific organizational capability}

Technological infrastructures include the technologies that facilitate and support knowledge management, such as business intelligence, collaborative learning and training, and its dissimilation, knowledge management for discoveries, and knowledge management for various scribing needs, etc (Goh, 2005; Alavi and Leidner, 2001). In effect, « Knowledge Management Technologies include those used for creating, storing, researching, distributing and analyzing structured and non-structured information " (Herschel and Jones, 2005, p.45). Knowledge management technologies are also the best way to support knowledge sharing in an organization, through it, knowledge sharing has become much easier than face to face, and by using it as a communication tool, the frequency of the communication and knowledge sharing would be more frequent and regular (Ngah, Tai, and Bontis, 2016). This will help employees in healthcare organizations to do their jobs and save time through better decision making and better problem solving; as well as creates a sense of community ties within the organization (Sonienwicki and Paliszkiewicz, 2019). It is in this context that technologies (clinical and administrative) are crucial in defining the competitiveness of healthcare organizations (Sharma, Wickramasinghe and Gupta, 2005). The tools and specific technologies can help a healthcare establishment develop its capabilities in the acquisition, storing, sharing, and internal use of knowledge by professionals and other types of healthcare workers (Oxbrow and Abell, 1998; Sharma, Wickramasinghe and Gupta, 2005).

According to Zaied (2012), "Knowledge-based technology is defined as the technical systems within an organization, which determine how knowledge travels throughout the enterprise and how knowledge is accessed ". It is essential to ensure that the employees of the organization are well informed about the general goals and objectives of the organization and how technology can facilitate the success of these objectives, before the implementation of the technologies of the organization. knowledge management, otherwise, it will lead to disappointing returns on technology investment (Zaied, 2012). The typical technological infrastructure of a healthcare establishment can be sub-divided into a group of systems that support: (Gargeya and Sorrel, 2005, p.50): 1 - Patient care; 2 - Administrative and regulatory processes; 3 Decision making and quality improvement; All these categories are, technologically speaking, supported by 1 Sound network architecture; 2- Hardware components; 3- Data architecture and software connectivity. To these ends, a sound technological architecture for knowledge management should be (Gargeya and Sorrel, 2005, p. 58): 1- Omnipresent, reliable, scalable, pliable, and secure; 2-Capable of supporting the transmission of data, both voice, and multimedia, including applications such as telemedicine and teleconferencing; 3- Use protocols and topology standards of the industry; 4 - Capable of supporting diverse requirements for infrastructure networks related to patient care, medical research, training, and administration; 5- Less costly as much for implementation as for operations. Note that information technology can improve the speed of integration and knowledge applications by automatically codifying organizational routines. Therefore, automatic systems like Workflow represent examples of applications of information technology that can help in reducing the need for communication and coordination and allowing more efficient use of organizational routines like documents, information, regulations, and activities (Alavi and Leidner, 2001). As well, expert systems based on rules are other means to capture and reinforce specific organizational procedures. Also, considering the plan for physical and information security (Gargeya and Sorrel, 2005, p.58), a sound architectural technology for knowledge management should use: 1- Fibre optics for the wiring and cables and install all electronic equipment in secure locals; Other means of protection such as firewalls are also desirable; 2- Authentication servers, security services, remote access, and e-mail management (e-mail Gateway). In 
addition, certain security rules must be respected (Gargeya and Sorrel, 2005, p.59): 1- Administrative procedures; 2- Physical security; 3- Security configuration management; 4- Security technical services; 5Security technical mechanisms; 6- Electronic signatures.

As for specific organizational structures for good knowledge management, Beveren (2003) notes that certain organizational structures in healthcare organizations are veritable obstacles to proper knowledge management: 1- Departmental structures within organizations are based on professional associations that are not designed for the required tasks; 2- Professionals in existing structures work essentially alone and, consequently, there is a lack of interdisciplinary fields in their ranks; 3- A dominant hierarchal structure, culturally entrenched, with many levels of management and where the distribution of information is very rigid, characterizes the majority of public sector organizations. Hence, " the theories of knowledge management are based on technological infrastructures that organize individual and collective knowledge as well as organizational structures that provide social conditions that encourage employees to share their knowledge and expertise » (Edge, 2005, p.45).

\subsection{Knowledge management process as a specific organizational capability}

Arias-Pérez, Tavera-Mesías, and Castaño-Serna (2019) defined KM processes as « cyclic mechanisms allowing to generate new knowledge, organizational learning and innovations ». The knowledge management processes comprise (Alavi and Leidner, 2001): 1- Knowledge creation; 2- Knowledge storage; 3- Knowledge transfer; 4- Knowledge application. This is also supported by Desouza (2005), who summarizes knowledge management processes in terms of creation, dissimilation, and utilization of knowledge within an organization. According to Raudeliūnienè, Davidavičienè, and Jakubavičius (2018), "Knowledge creation means the organization's ability to create new and useful ideas and solutions, related to the various aspects of organizational activity, from products and technological processes to management practices ". It is also important to note that knowledge creation refers to the identification of the internal or external source and by the extraction procedures that serve as inputs to the knowledge management process. As well, the capture and the storage of knowledge are the sums of the procedures and processes of their transfer to data and storage easily read by computer technology. Such codifying or transfer to data form of explicit knowledge calls upon the transfer of explicit knowledge codified in different formats to an electronic document format (Desouza, 2005). Regarding the codification of tacit knowledge, it consists of converting them to explicit knowledge in electronic form (Desouza, 2005). Thus "The use of a centralized repository facilitates the conservation of knowledge, eliminates the duplication of effort at the departmental or organizational level, and reduces costs " (Desouza, 2005, p.16). The knowledge repository permits members of an organization to use it at their leisure whenever the need arises. In effect, once stored, the information and the knowledge of the organization can be made available to facilitate access to other members of the organization (Desouza, 2005). However, only authorized persons will be allowed to manipulate the information and knowledge so stored. In regards to innovation, Weixu, Eugene and Atsuhi, (2019), argue that " KM, including knowledge acquiring, also seen as knowledge creation, sharing, and application, is considered the core driving power of administrative innovation and supports the new administrative innovation constantly. Likewise, the coordinating mechanisms of KM encourage organizational members to transfer their individual knowledge to collective knowledge and supports transforming knowledge into organizational innovative capabilities».

Regarding the use and the application of knowledge, Alavi, and Leidner (2001, p.122) state that " the important aspect of the theory on knowledge creation within an organization is the competitive advantage inherent in knowledge application as much as the knowledge itself ". As well, good process management requires specific organizational capabilities. In such a framework, Grant (1996) identifies three primary mechanisms for the integration of knowledge in the creation of organizational capabilities: Organizational directives, organizational routines, and the type of tasks given to teams. Organizational directives refer to the set of rules, standards, procedures, and instructions developed from converting tacit knowledge from specialists in explicit knowledge and in integrated knowledge for efficient communication (Alavi and Leidner, 2001; Demsets, 1991). Furthermore, by improving the size of individual internal networks and by increasing the number of organizational memories available, information technologies can permit organizational knowledge to be applied to the moment chosen or fixed (Alavi and Leidner, 2001).

It is important to know that the knowledge management process can be more effective in an organization if the employees are competent and motivated. (Raudeliūnienè, Davidavičienè, and Jakubavičius, 2018). The effectiveness of the knowledge management process depends on the competence, motivation of employees, and the infrastructure of information and communication technologies. In addition, the authors argued that 
« these knowledge management processes (the process of gaining valuable knowledge, disseminating this knowledge in the organization, timely delivery, and commercial application) is important in order to improve the organization's innovative results » (Raudeliūnienè, Davidavičienė, and Jakubavičius, 2018).

\subsection{Knowledge management competencies as specific organizational capabilities}

This dimension refers to the nature of the competencies required to manage and execute knowledge management processes: 1 - The culture in knowledge management; 2 - The motivation towards knowledge management; 3- The rewards of knowledge management; 4 - The incentives of knowledge management.

The new culture of healthcare organizations is to counter the existing culture of resistance and protection of individual knowledge (Svieby and Simons, 2002; Beveren, 2003). In effect, these organizations have the same obstacles to overcome as those in the public sector regarding the culture of collaboration in the sharing of individual knowledge as opposed to the private sector (Svieby and Simons, 2002): "There is a strong resistance to change both on an individual level and on a senior management (director) level that prevents any adaptation and reactions to environmental requirements " (Beveren, 2003, p.92). Conversely, a healthcare establishment should be an organization where the patient is at the forefront of care dispensed at the hospital. For this reason, the cooperation by the exchange of data, information, and knowledge between healthcare professionals centered on the patient and the hospital administration turns out to be crucial and supposes a change in the organizational culture (Beveren, 2003). The current autonomous culture and the "bunkers of knowledge » should be replaced by a new culture that requires cooperation, communication, training, and teamwork (Beveren, 2003; Brakensiek, 2002).

The motivation is itself the ability to facilitate continual processes for sharing and renewing knowledge, the ability to develop the human resources, and the organizational culture that facilitates the sharing of knowledge, along with the ability to utilize the available technologies to create, share, and document the knowledge. Similarly, Alavi and Leidner (2001) remind us that these organizations require a profound cultural renaissance because, traditionally, they reward professionals according to their individual performance and their competency, and not according to their capability to learn and to share what they know or have learned. As well, Alavi and Leidner (2001, p.127) affirm that " incentives are very important to remove certain major barriers to realizing knowledge storage ». These barriers include 1- The lack of time for employees to contribute to the creation of their knowledge; 2 - the corporate culture which historically has never rewarded employees that contribute to the creation of their knowledge and then share with others.

The ability to facilitate the continual processes of sharing knowledge and their renewal, the ability to develop the human resources and the organizational culture that facilitates the sharing of knowledge, and the ability to utilize available technologies for the creation, sharing, and documentation of such knowledge are a few examples of the competencies required for sound knowledge management (Malhotra, 1997). As well, recent studies support that the development of specific organizational capabilities for knowledge management is best assured by a maturity model of specific capabilities (Ehms and Langen, 2001; Klimko, 2001; Kaner and Karni, 2004; Harigopal and Satyadas, 2001; Dayan and Stephen, 2006; Berztiss, 2002; Johnson and Brodman, 2002; Dekleva and Drehmer, 2001). Hence, the following section discusses the concept of a maturity model for specific organizational capabilities for knowledge management.

\subsection{Maturity models for knowledge management}

The concept of a maturity model, in this study, stems from the management learning school that promotes the development of organizational competencies by a learning process that increases over time and which has as its aim to shape the models for the development of organizational competencies (Cyert and March 1963; Nelson and Winter, 1982; Burgelman, 1988; Cohen and Levinthal, 1990 citation by Préfontaine, 1994). In effect, organizational learning is the way companies enrich and organize knowledge and the tasks around the activities and the culture and develop effectiveness for improving the competencies of their workforce. " Organizational maturity is achieved when the KM processes are effectively managed and applied " (AriasPérez, Tavera-Mesías, and Castaño-Serna, 2019). It is in this perspective that Peppart and Ward $(2004$, p.178) propose a competency model for information technology and argue that the expression for particular competencies depends: « (1) Persons that apply their knowledge; (2) The way by which people integrate their knowledge; (3) How people interact with others; (4) The way by which people coordinate their activities ". The work of Venkatraman (1994), Dekleva and Drehmer (2001), Luftman et al. (2004), Peppart and Ward (2004), and St-Amant and Renard (2004) on information technology and management supports the improvement of 
performance levels that an organization may attain after developing specific organizational capabilities for knowledge management.

\section{Presentation of the Model}

Henceforth, we utilize the maturity models of the KMC developed as shown in Figure 1. This model considers five levels of maturity and is based on two hypotheses evoked by Venkatraman, (1994): 1- The lower the level of maturity of specific organizational capabilities for knowledge management of an organization, the lower is the expected benefits, whereas 2- The higher the level of maturity of specific organizational capabilities for knowledge management of an organization, the higher are the expected benefits.

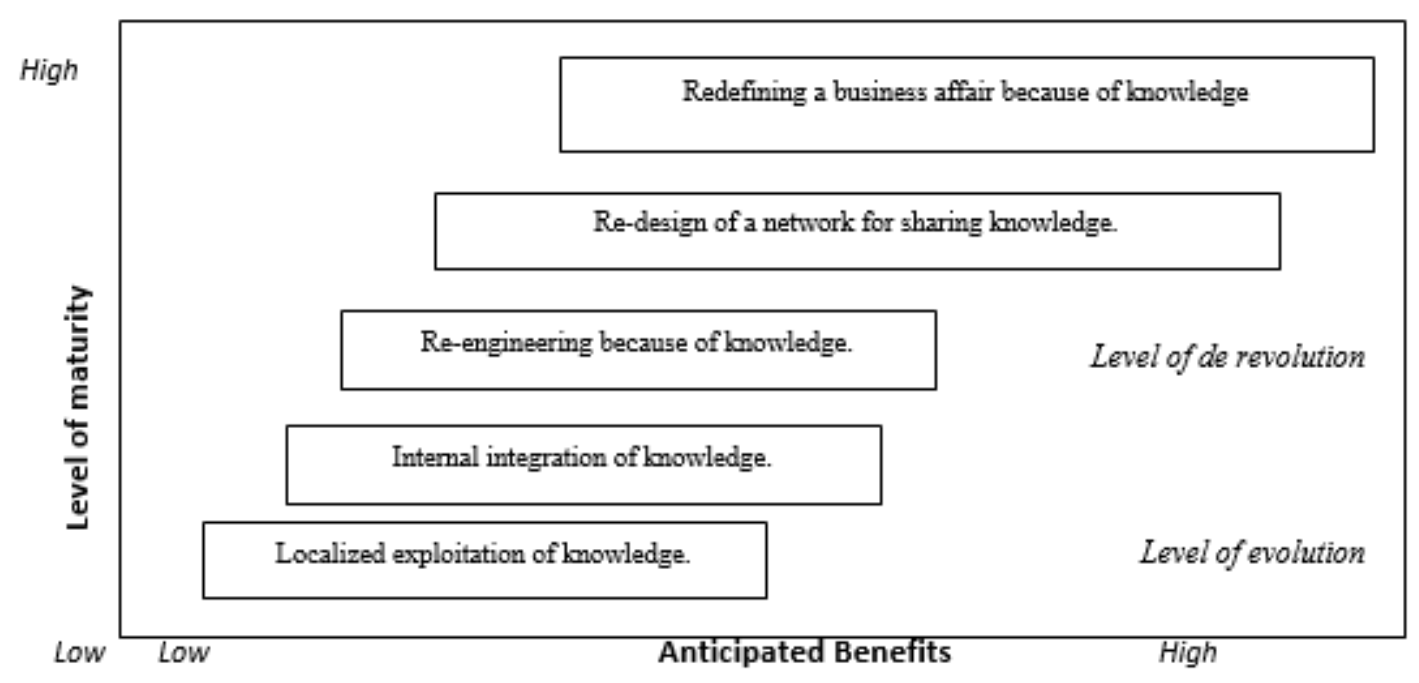

Figure 1: Maturity level of organizations by KM (evoked by Venkatraman, 1994)

We observe that the maturity levels of specific organizational capabilities of knowledge management of an organization are divided into two large categories: 1- Level of Evolution (level 1: localized exploitation, and level 2: internal integration); 2- Level of revolution (level 3: re-engineering, level 4: re-design of networks, and level 5: redefining business affairs). Hence, to better understand each level of the KMCMM, we will use the three principal dimensions as presented in the preceding section. Since we have stressed that knowledge management differs from one organization to another, from one industry to another, and from one reality to another, the following sub-section briefly presents the healthcare system of the Democratic Republic of Congo.

\subsection{Summary of the healthcare system of the Democratic Republic of Congo}

The Democratic Republic of Congo (DRC) is a vast country in central Africa that extends from the Atlantic Ocean to the eastern plateau and represents the major part of the Congo River basin. With an area of $2,345,000 \mathrm{~km} 2$, a population of more than $62,600,000$ belonging to 500 ethnic black African groups, the DRC has 26 provinces with Kinshasa as its capital. With regards to healthcare, the DRC is a vast territory with social indicators that are very worrisome: 1- The infant mortality rate has gone from 125 per thousand in 1990 to 170 per thousand in 2000; 2- The childbirth mortality rate has gone from 800 deaths per 100,000 births in 1990 to 2000 deaths per 100,000 births at present (1990); 3- The average lifespan was 42 years in 2002 compared to an African average of 51 years; 4 - Access to basic healthcare is less than 26 percent.

In effect, the national healthcare policy is based on the following principles: 1 - The quality of care and services; 2- The efficiency and effectiveness of projects and healthcare development programs; 3- The coordination within and between healthcare sectors that dispense care; 4- Community participation; 5- Decentralizing decision making; 6- Decentralization of healthcare service facilities; 7- Integration of specialized services as part of basic healthcare services. 
Thus, on a purely operational plan, the DRC healthcare system has adopted clear policies. The DRC healthcare system is operated, according to the operational plan, by the public, private, community, and religious organizations.

For the scope of the present study, two hospitals, one public, and one private have retained our attention. They are, respectively, the Kinshasa Reference Clinic and the Libanga Hospital Center, both located in Kinshasa. Note that the healthcare organizations and the entire sanitation system need to develop specific organizational capabilities that will help capture data, information, and knowledge necessary to provide quality care to patients. This would improve the efficiency and effectiveness of these organizations by a better circulation of information and better sharing of knowledge between different healthcare and sanitary workers. Consequently, a systematic diagnostic of existing organizational capabilities in these areas is required to accomplish such a task.

\section{Methodology: Methods and design of Case Study}

« Research methodology is a way to systematically solve the research problem. It may be understood as a science of studying how research is done scientifically " (Kothari, 2004, p.8). Also, Gauthier and Bourgeois (2016, pp.9), added that the research methodology includes at both the structure of the mind and form of the research and the techniques used to practice this spirit and this form (Fortin and Gagnon, 2016, p.190), point out that the qualitative research methodology is used to answer research questions related to complex situations or questions related to the exploration, description, and understanding of phenomena. Therefore, we chose this methodology to assess and understand the knowledge management capabilities of our health organizations under study.

Regarding the data collection of our study, we used a few methods: observations, documentary, and questionnaire as well as interviews to collect data from the health organizations and the Ministry of Health of the Democratic Republic of Congo. The analysis of our collected data will help us to produce a detailed description of our case study as well as its context as suggested by Fortin and Gagnon (2016, p.374).

According to Creswell (2009), a research design is at the intersection of the search strategy and search method. In other words, the design is inspired by the research strategy to establish the general framework that guides the research method (Bryman, 2012). We have chosen a search strategy qualitative. This presents the general characteristics among which exploration and description are the main ones. The characteristics of our research strategy chosen to conduct our research are the case study (Fortin and Gagnon, 2016, p.190).

According to Yin (1994), the case study is empirical research that analyses a contemporary phenomenon in its natural state, whenever the lines between the context and the phenomenon are not clear, and where multiple sources of proof are utilized. Other authors also argue that the case study is a research method that involves an in-depth analysis of one or more entities. It also consists of taking stock of a particular real situation, put in context, and analyzing it to discover how the phenomena that interest the researcher appear and evolve (Fortin and Gagnon, 2016, p.197). Figure 2 shows the developmental stages for the case study.

The qualitative research strategy of our study aimed to understand and assess the level of knowledge management capacities in these studied health organizations, and then, we also seek to evaluate the capacities of these health organizations to capture, transfer and dissociate the data information, and their medical knowledge. As well as their knowledge management sharing based on KMCMM.

This study has recourse to various data sources: (documents and Web site), questionnaire, and a few interviews. The paper documents and Web pages of organizations studied along with those of the Ministry of Health of the Democratic Republic of Congo allowed us to compress more thoroughly the organizational and sector-based context of the material. Thus, Contandriopoulos et al. (1990) identified three large sources of data furnished by subjects: use of documents, observations by the researcher, and use of data during interviews. 


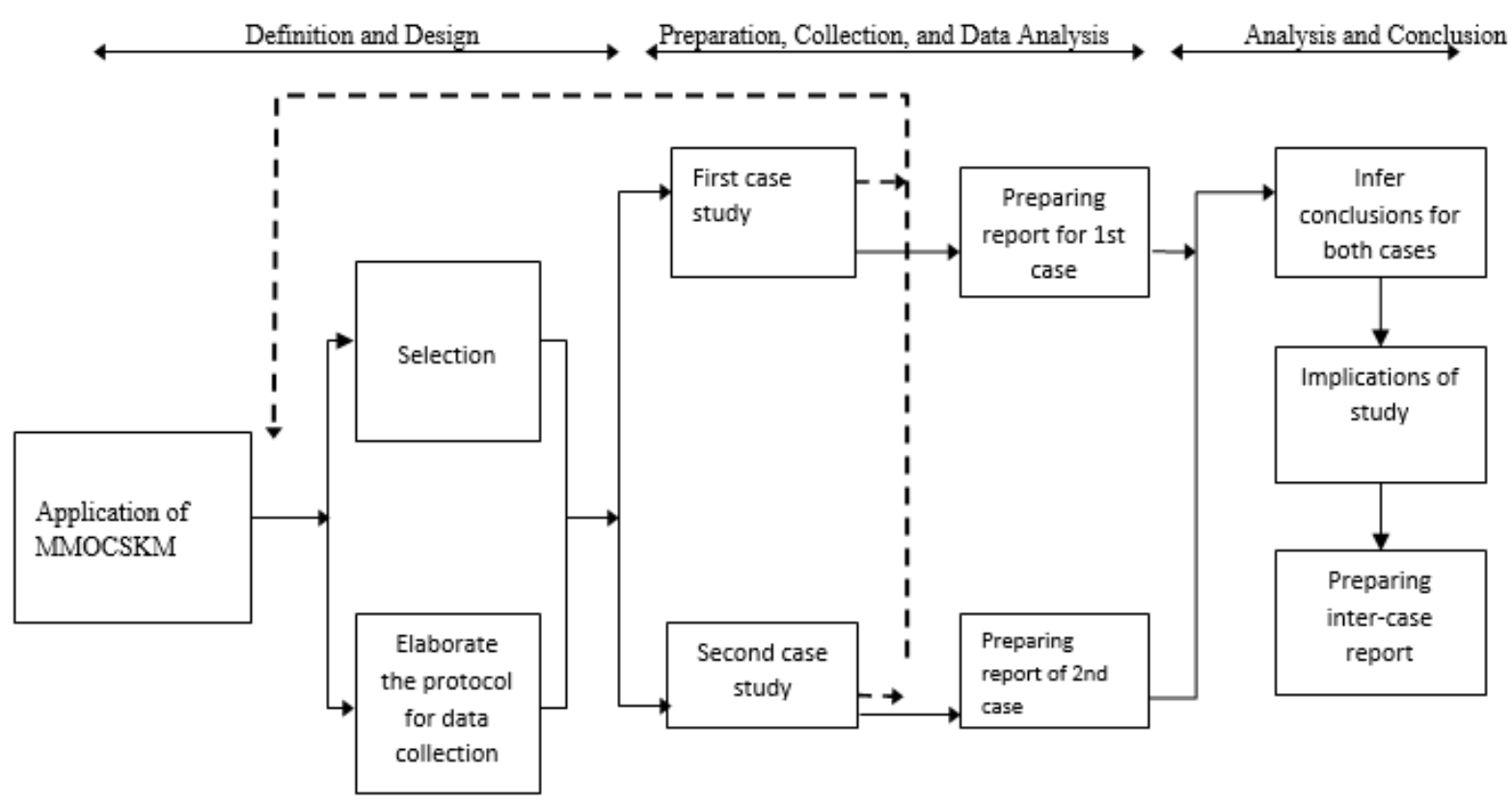

Figure 2: Developmental stages for case study (as per Yin, 1994)

\section{Sequence and results of case study within the two healthcare organizations}

This section will present the results of a case study of two healthcare organizations employing a maturity model for specific organizational capabilities of knowledge management (KMCMM) as proposed by Booto Ekionea \& Abou-Zeid (2005). This case study thus aims to identify the maturity level reached by each of the two organizations for knowledge management capabilities in order to determine the challenges ahead for each organization. Therefore, in addition to the consolidated results presented in Table 8, the first part will examine the sequence and the results of the research at the Libanga Hospital Center (LHC), while the second part will examine the sequence and the results of the research at the Kinshasa Reference Clinic (KRC).

The LHC is a private organization yet social in nature. Opened in 1991 to help the local population, today it has a capacity of 200 beds distributed in air-conditioned rooms with autonomous sanitary installations. The LHC offers surgery, gynecology, obstetrics, neonatal, dermatology, cardiology, gastro-entomology, Hemi-dialysis, internal medicine, ophthalmology, ORL, orthopedics, urology, pediatrics, Hemi-oncology, dentistry, laboratory and medical imaging, physiotherapy, and radiotherapy, along with emergency and intensive care services.

Table 2: KMCMM - Applied in LHC and KRC

\begin{tabular}{|l|l|c|c|}
\hline No & \multirow{2}{*}{ KM Capabilities Features (characteristics) } & \multicolumn{2}{|c|}{ KMCMM Level Reached } \\
\cline { 3 - 4 } & & LHC & KRC \\
\hline 1 & Technology Infrastructures & 1 & 1 \\
\hline 2 & Specific Structures & 2 & 2 \\
\hline 3 & Knowledge Generation Processes & 2 & 2 \\
\hline 4 & Knowledge Manipulation Processes & 2 & 1 \\
\hline 5 & Knowledge Application Processes & 2 & 1 \\
\hline 6 & KM Culture & 2 & 1 \\
\hline 7 & KM Motivation & 3 & 1 \\
\hline 8 & KM Rewards & 2 & 1 \\
\hline 9 & KM Inciting & 1 & 1 \\
\hline
\end{tabular}

At the end of the inquiry, and following the format of the questionnaire, the following results were observed as shown on tables 3 and 4 : 
Table 3: Application of KMCMM within the LHC

\begin{tabular}{|l|l|l|}
\hline Dimensions & Characteristics & LHC Diagnosis \\
\hline $\begin{array}{l}\text { KM } \\
\text { Infrastructure }\end{array}$ & $\begin{array}{l}\text { Technology } \\
\text { Infrastructures }\end{array}$ & $\begin{array}{l}\text { 1- The professionals work manually and all of them use the paper medium; 2- } \\
\text { The Web site does not facilitate the information exchange; 3- Absence of } \\
\text { information and knowledge exchange policies between professionals; } 4- \\
\text { Knowledge management efforts duplicated. }\end{array}$ \\
\cline { 2 - 3 } & $\begin{array}{l}\text { Specific } \\
\text { Structures }\end{array}$ & $\begin{array}{l}\text { 1- The medical daily meetings in the morning as KM structure are not sufficient } \\
\text { to guarantee a significant long-term KM support; 2- Daily meetings are a good } \\
\text { point for good knowledge management. }\end{array}$ \\
\hline \multirow{5}{*}{ KM Processes } & $\begin{array}{l}\text { Knowledge } \\
\text { Generation } \\
\text { Processes }\end{array}$ & $\begin{array}{l}\text { 1- Absence of IT dedicated to KM and lack of their integration with medical } \\
\text { technologies; 2- The knowledge exchanges are done verbally, or they are } \\
\text { consigned in the paper reports. }\end{array}$ \\
\cline { 2 - 3 } & $\begin{array}{l}\text { Knowledge } \\
\text { Manipulation } \\
\text { Processes }\end{array}$ & $\begin{array}{l}\text { 1- The knowledge manipulation processes are limited to the only entities } \\
\text { dedicated to patient care and neither are documented nor evaluated. }\end{array}$ \\
\cline { 2 - 3 } & $\begin{array}{l}\text { Knowledge } \\
\text { Application } \\
\text { Processes }\end{array}$ & $\begin{array}{l}\text { 1- The knowledge, information, and data sources are rudimentary and limited; 2- } \\
\text { The rare knowledge exchanges between professionals are done at work } \\
\text { meetings and within training seminars. }\end{array}$ \\
\hline \multirow{5}{*}{ KM Skills } & KM Culture & $\begin{array}{l}\text { 1- The KM initiatives are not the result of written and observed strategic } \\
\text { thinking; } 2 \text { - KM practices are isolated. }\end{array}$ \\
\cline { 2 - 3 } & KM Motivation & $\begin{array}{l}\text { 1- People and organizational entities are not motivated to knowledge } \\
\text { management. }\end{array}$ \\
\cline { 2 - 3 } & KM Rewards & 1- Lack of clear policy regarding KM rewards. \\
\cline { 2 - 3 } & KM Inciting & 1- Absence of KM incentive measures. \\
\hline
\end{tabular}

The Kinshasa Reference Clinic is the reference hospital for the city of Kinshasa whose population is evaluated at more than eight million people.

Table 4: Application of the KMCMM within the KRC

\begin{tabular}{|c|c|c|}
\hline $\begin{array}{l}\text { Dimensions } \\
\text { studied }\end{array}$ & $\begin{array}{l}\text { Characteristic } \\
\text { s }\end{array}$ & Maturity Levels of the KMC attained by the KRC \\
\hline \multirow[t]{2}{*}{$\begin{array}{l}\text { KM } \\
\text { Infrastructur } \\
\text { es }\end{array}$} & $\begin{array}{l}\text { Technology } \\
\text { Infrastructure } \\
\text { S }\end{array}$ & $\begin{array}{l}\text { The exploitation of technological infrastructure for knowledge management is } \\
\text { absent or limited and localized since the few information equipments available and } \\
\text { functional at the KRC is used exclusively for bureaucratic, accounting, budgeting, } \\
\text { accounts payable, invoicing patients, tracking professional fees of doctors and } \\
\text { nurses, stock and invoicing, and allocation of the main ledger, etc. }\end{array}$ \\
\hline & $\begin{array}{l}\text { Specific } \\
\text { Structures }\end{array}$ & $\begin{array}{l}\text { There is an emergence of specific structures for knowledge management but } \\
\text { isolated and not integrated, for there are regular medical meetings held. }\end{array}$ \\
\hline \multirow[t]{3}{*}{$\begin{array}{l}\text { KM } \\
\text { Processes }\end{array}$} & $\begin{array}{l}\text { Knowledge } \\
\text { Generation } \\
\text { Processes }\end{array}$ & $\begin{array}{l}\text { There is an emergence of processes for knowledge generation at the level of certain } \\
\text { internal practices since there are meetings and scientific discussions on medical } \\
\text { issues or questions. }\end{array}$ \\
\hline & $\begin{array}{l}\text { Knowledge } \\
\text { Manipulation } \\
\text { Processes }\end{array}$ & $\begin{array}{l}\text { The processes for knowledge manipulation are unpredictable, weakly controlled, } \\
\text { and rudimentary since hospital directors do little to facilitate such processes. }\end{array}$ \\
\hline & $\begin{array}{l}\text { Knowledge } \\
\text { Application } \\
\text { Processes }\end{array}$ & $\begin{array}{l}\text { There is an absence of a formal process for knowledge application, and the reaction } \\
\text { is case by case since data, information, and knowledge are not integrated. }\end{array}$ \\
\hline \multirow[t]{4}{*}{ KM Skills } & KM Culture & $\begin{array}{l}\text { Culture and an organizational vision for knowledge management are absent because } \\
\text { of a lack of policies and specific strategies. }\end{array}$ \\
\hline & $\begin{array}{l}\text { KM } \\
\text { Motivation } \\
\end{array}$ & $\begin{array}{l}\text { Personnel applies locally their knowledge without assistance from the organization } \\
\text { since efforts are rarely made except by a few persons or organizational entities. }\end{array}$ \\
\hline & KM Rewards & $\begin{array}{l}\text { The organization offers little motivation or reward in human resources towards } \\
\text { knowledge management. }\end{array}$ \\
\hline & KM Inciting & $\begin{array}{l}\text { Success depends on the competencies of a few individuals and organizational } \\
\text { entities. }\end{array}$ \\
\hline
\end{tabular}

\section{Discussions and Conclusion}

For this case study, Yin (1994) identifies three methods of analysis: (1) Matching a model to reality; (2) constructing an explanation; (3) chronological series. The method of analysis retained is the matching of a 
model to reality, which consists of comparing a theoretical model (prediction) with an empirical model (observed) to determine the conformity between the model and the empirical reality.

Concerning the present study, the healthcare sector was chosen, and the KMCMM was applied to two healthcare organizations in order to measure its capability to diagnose an organization and to confirm the considerations at the beginning of the study.

Thus, to understand the capabilities of a research strategy to produce results that can be applied more generally to other populations, contexts, and periods, which was not our objective in this study, one must ask to what extent are the results obtained influenced by the particular context in which the research was conducted. The more solid the theory on which the research is based and the more coherent are the empirical results obtained in a context with the theoretical hypothesis, then the more these results can be generalized in other types of contexts.

For each dimension of the KMC and by comparing the results of the case studies of both organizations (see Table 2), the result of the empirical research showed us that the two organizations studied are limited in terms of KM infrastructure, which includes (technological infrastructure and specific structures), therefore, this can have a huge impact in the dimension of KMC as the technology plays a key factor in knowledge sharing in an organization. Even though the specific structures have shown a good result (see table 2), this may have a positive impact on KM in their organization, but the capacity of employees to share and exchange knowledge through technological support in both organizations is limited and may affect their capacity of knowledge exchange and sharing. According to our research results, this aspect can reduce the development of knowledge sharing and delay these organizations to reach KMC maturity. Regarding the knowledge processes, empirical research has shown a positive result across both organizations in terms of knowledge generation processes, which shows the motivation for knowledge creation in both organizations. It is important to know that knowledge creation means the capacity of the organization to create new and useful ideas and solutions, related to various aspects of organizational activity (Raudeliūnienè, Davidavičienè, and Jakubavičius, 2018). Comparing both organizations in terms of knowledge processes, The LHC has shown more positive results than the KRC. The overall review of the KMC in both organizations shows that it is possible to confirm or invalidate the observations made at the onset: " 1- the more the maturity level of organizational capabilities specific to knowledge management of an organization is low, the more the expected benefits are low, 2- the more the maturity level of organizational capabilities specific to knowledge management of an organization is higher, the more the expected benefits are higher $»$.

When the question is asked why a hospital needs a new system for knowledge management, Rubenstein and Geisler (2005, p. 44) answer by proposing eight reasons: " 1- create a bridge and eliminate the isolation between specialists and other organizational support entities; 2- learn from one's experience and that of other organizations; 3- avoid repeating the same errors or mistakes in many areas, notably disease management, infection control, ill-advised use of instruments and the duplication of expensive equipment; 4- support training at all levels; 5- support organizational entities that are weak or have fewer resources with the experience from organizational units that are richer and have better resources; 6 - share ideas and " tricks of the trade "; 7- avoid being dysfunctional on the organizational design level, staffing, and workflow; 8- change the methods for improving productivity, cost reduction, and patient services ".

Thus, this study had identified as its objective to apply the maturity model to specific organizational capabilities for knowledge management (KMCMM) to assist the healthcare organizations studied conduct a diagnostic of their capabilities and to develop new specific organizational capabilities in knowledge management (KMC). This study proves that the diagnostic of the KMC could not be better conducted without help from a KMCMM by taking into account the three main dimensions of the KMC, that is, knowledge management infrastructures, knowledge management processes, and knowledge management competencies by healthcare personnel.

According to Contandriopoulos et al. (1990), internal validity is based on the capability of a study to put a litmus test, simultaneously, an ensemble of relations that comprise a theoretical model. The internal validity is assessed by (1) the quality, complexity, and the exhaustive nature of the theoretical structure on which the study is based; (2) the adequacy between the chosen mode of analysis and the theoretical model tested. It is, therefore, the comparison of results from the two healthcare studies that demonstrate that the two 
hypotheses at the onset were confirmed (Venkatraman, 1994): «1- when the level of maturity of specific organizational capabilities in knowledge management of an organization is low, the anticipated benefits are also low; 2 - whereas the more the level of maturity of specific organizational capabilities in knowledge management is high, the anticipated benefits will also be high ". It was thus noted that the absence of the limited levels of KMC in both organizations studied prevented them from maximizing the benefits obtained from sound knowledge management.

According to Edwards (2011), organizations, where the knowledge management has been successfully reached maturity level, are happy and may have followed the " thinking process » which, suggested 8 steps of actionoriented view of knowledge management initiative " identify processes, design processes, implement processes, facilitate processes, monitor processes, analyze processes, mend processes and retire processes " (Edwards,2011). Applying these steps could drive an efficient KMC in an organization. Our KMCMM will certainly help to assess, take out all the aspects that are holding back the development of KM and finally lead an organization to reach the KMC maturity level.

In conclusion, this paper aimed to provide best practices and improve the KM of health professionals and organizational health outcomes and general outcomes at the level of the health system in sub-Saharan Africa and the health organizations of the Democratic Republic Congo. Besides, it will help organizations determine their level of KMC maturity and adjust their strength according to their goals. Also, it supports the implementation of information technology to strengthen KM healthcare organizations in general. Such a system will bring innovation and help build a culture of innovation in all organizations and support communications that can help disperse knowledge, provide better decision making, better performance measurement, and lead to competitive advantage (Alrahbi et al., 2020).

Finally, it is possible that the results obtained from the two case studies in the healthcare and clinical sectors have a limited scope and cannot be generalized. This was not the objective of the present study. Hence, it would be enriching for the research to come to lean on larger applications of the KMCMM to find, if possible, standardization for an industry or a given context.

\section{References}

Abou-Zeid, E. S., 2002. A strategic alignment model for knowledge management. Information Resources Management Association International Conference Proceedings IRMA-2002, Seatlle,WA, (USA), May 19-22.

Abou-Zeid, E.S., 2003. Developing business aligned knowledge management strategy. In E. Coakes (Ed.), Knowledge Management: Current Issues and Challenges: Hershey: IRM Press, pp. 156-172.

Ahn, J. and Chang, S., 2005. Product and process knowledge in the performance-oriented Knowledge Management approach. Journal of Knowledge Management, 9(4), pp. 8-18.

mAlavi, M. and Leidner, D., 2001. Knowledge management and knowledge management systems: conceptual foundations and research issues, MIS Quarterly, 25(1), pp. 107-136.

Alrahbi, D., Gupta, S., Modgil, S., Khan, M and Jabbour, C., 2020. Challenges for developing health-care knowledge in the digital age. Journal of Knowledge Management. Vol. ahead-of-print No. ahead-of-print. https://doi.org/10.1108/JKM03-2020-0224

Antrobus, S. 1997. Developing the nurse as a knowledge worker in health-learning the artistry of practice. Journal of Advanced Nursing, 25(4), pp. 823-829.

Arias-Pérez, J., Tavera-Mesías, J., and Castaño-Serna, D., 2019. Knowledge management maturity: development of maturity scales and interaction between key areas. European Research Studies, 22(4), pp. 493-517.

Armbrecht, R., Chapas, R., Chappelow. C., Farris. F., Friga, P., Hartz, A., Mcllvaine, E., Postle, R., and Whitwell, E., 2001. Knowledge management in research and development. Research Technology Management 44(4), pp. $28-48$.

Barney, J. ,1991. Firm resources and sustained competitive aadvantage. Journal of Management, 17(1), pp. 99-120.

Berztiss, A., 2002. Capability maturity for knowledge management. IEEE, 13th International Workshop on 2-6 Sept., pp. $162-166$.

Beveren, V., 2003. Does health care for knowledge management? Journal of Knowledge Management, 7 (1), pp. 90-95.

Booto, Ekionea and Abou-Zeid, E., 2005. Knowledge management and sustained competitive advantage: a resources based analysis. Information Resources Management Association International Conference Proceedings IRMA-2005, San Diego (USA), May 15-18.

Brakensiek, J., 2002. Knowledge management for EHS professionals. Occupational Health \& Safety, 71 (1), pp. 72-74.

Bryman, A,. 2012. Social research methods (4th ed). Oxford, UK: Oxford University Press.

Burgelman, A., 1988. Strategy making as a social learning process: the case of internal venturing. Interface, 18(3), pp. 7485.

Chase., 1998. Knowledge navigators. Information Outlook, 2(9), pp. 18-29. 
Contandriopoulos, A.-P., Champagne, F., Potvin, L., Denis, J-L., and Boyle, P., 1990. Savoir préparer une recherche: la définir, la structurer, la financer. Montreal : Presse de l'Université de Montréal.

Creswell, J. W., 2009. Research design: Qualitative, quantitative and mixed methods approaches (3rd ed.). Thousand Oaks, CA:Sage Publications, Inc.

Cyert, M. and March, G., 1963. A behavioural theory of the firm. New Jersey: Prentice-Hall Inc.

Dayan, R. and Stephen, E., 2006. KM your way to CMMI. Journal of Knowledge Management, 10(1), pp.69-80.

Dekleva, S. and Drehmer, D., 2001. Measuring software engineering evolution: a rash calibration. Information Systems Research, 8(1) pp. 95-104.

Desouza. 2005. Knowledge management in hospitals. In: N. Wickramasinghe, J.N.D. Gupta and S. K. Sharma, (Eds.), Creating knowledge based healthcare organizations, Hershey, PA: Idea Group Publishing, pp. 14-28.

Earl, M., 2001. Knowledge management strategies: toward a taxonomy. Journal of Management Information Systems, 18(1), pp. 215-233

Edge, K. 2005. Powerful public sector knowledge management: a school district example. Journal of Knowledge Management, 9(6), pp. 42-52.

Edwards, J., 2011. A process view of knowledge management: it ain't what you do, it's the way that you do it. Electronic Journal of Knowledge Management, 9(4), pp.297-306

Ehms, K. and Langen, M., (2001). Holistic development of knowledge management with KMMM. In: Proceedings of the fourth IC world Congress. Hamilton, Canada, January 17- 19. Hamilton : Siemens AG.

Eisenberg, H., 2002. Transforming hospital into knowledge management centres. Available at: http://www.syntrek.com/kmppt/. [Accessed February 2004]

Fortin, M-F. and Gagnon, J., 2015. Fondements et étapes du processus de recherche : méthodes quantitatives et qualitatives ( $3 r d$ ed). Montreal : Chenelière Education

Gargeya and Sorrel., 2005. Moving toward an e-Hospital , In: N. Wickramasinghe, J. N. D., Gupta, and S. K. Sharma, (Eds.), Creating knowledge-based healthcare organizations, Hershey, PA:,Idea Group Publishing, pp. 50-64.

Gauthier, B and Bourgeois, I., 2016. Recherche sociale : de la problématique à la collecte des données. (6e éd.). Montreal: Presses de l'Université du Québec.

Goh, A., 2005. Harnessing knowledge innovation: an integrated management framework. Journal of Knowledge Management, 9(4), pp. 6-18.

Grant, R., 1996. Toward a knowledge-based theory of the firm. Strategic Management Journal, 17(Winter Special Issue), pp. 109-112.

Harigopal, U. and Satyadas, A., 2001. Cognizant enterprise maturity model (CEMM). IEEE, 31(4), pp. 449-459.

Hersch, W. and Lunin, L., 1995. Perspectives on medical informatics: information technology in healthcare - introduction and overview. Journal of American Social Infrastructure Science, 46(December), pp. 726-727.

Herschel, R. and Jones, E., 2005. Knowledge management and business intelligence: the importance of integration. Journal of Knowledge Management, 9(4), pp. 45-55.

Jonson, D. and Brodman, J., 2002. Applying CMM project planning practices to diverse environments. IEEE, Software, 17(4), pp. 40-47.

Kaner, M., and Karni, R., 2004. A capability maturity model for knowledge-based decision-making. Information Knowledge Systems Management, 4, pp. 225-252.

Klimko., 2001. Knowledge management and maturity models: building common understanding. Proceedings of the Second European Conference on Knowledge Management, Bled Slovenia, November 8-9.UK: MCIL. pp. 269-278.

Kothari, C. R., 2004. Research methodology: methods \& techniques: 2nd rev. ed. New Delhi: New Age International.

Lewis, D., 1995. Insaisissable connaissance. Trad. fr. dans Dutant et Engel, eds, Philosophie de la connaissance, Paris, Vrin.

Luftman, J., Bullen, C., Liao, D., Nash, E., and Neumann, C., 2004. Managing the IT resource: leadership in the information age. Upper Saddle River, NJ: Pearson, Prentice Hall.

Mbeva, J-B., Schirvel, C., Wodon, A., and Godelet, E., 2014. Réforme des structures intermédiaires de santé en République démocratique du Congo. Santé Publique 26(6) p.849. DOI: 10.3917/spub.146.0849

Nelson, R. and Winter, S. ,1982. An evolutionary theory of economic change. Cambridge: Belknap Press.

Ngah, R., Tai, T., and Bontis, N., 2016. Knowledge management capabilities and organizational performance in roads and transport authority of Dubai: the mediating role of learning organization. Knowledge and Process Management, 23(3), 184-193. https://doi.org/10.1002/kpm.1504

Nonaka, I., 1998. The knowledge-creating company. Harvard Business Review, July/August, Special issue on Knowledge Management, pp. 21-46.

Oxbrow, N. and Abell, A., 1998. Putting knowledge to work: what skills and competencies are required? In: SLA State-ofthe-Art Institute, Knowledge Management: A New Competitive Asset. Special Libraries Association: Washington, DC.

Pauker, S., Gorry, A., Kassirer, J. and Schwart, W., 1976. Towards the simulation of clinical cognition: taking a present illness by computer. American Journal on Medicine, 65, pp. 981-996.

Pavia., L., 2001. The era of knowledge in health care. Health Care Strategic Management, 19(2), pp. 12-13.

Peppart, J. and Ward., J., 2004. Beyond strategic information systems: towards an IS capability. Journal of Strategic Information Systems, 13(2), pp. 167-194.

Prax., J-Y., 2003. Le manuel du knowledge management. Paris : Dunod..

Préfontaine, L,. 1994. Les compétences organisationnelles favorisant l'innovation technologique dans un contexte de PME manufacturières. [Thèse de doctorat, Université du Québec à Montréal]. 
Raudeliūnienė, J., Davidavičienè, V., and Jakubavičius, A., 2018. Knowledge management process model. Entrepreneurship and Sustainability Issues, 5(3), 542-554. https://doi.org/10.9770/jesi.2018.5.3(10)

Riedge., A and Lindsay. N., 2006. Knowledge in the public sector: stake: stakeholder partnerships in the public policy development. Journal of Knowledge Management, 10(3), pp. 24-39.

Rubenstein., $\mathrm{H}$ and Geisler., E., 2005. How to start or improve a KM system in hospital or healthcare organization. Hershey, PA : IGI Global.

Sharma, S. K., Wickramasinghe, N. and Gupta, J. N. D., 2005. Creating knowledge based healthcare organizations, Hershey, PA : Idea Group Publishing, pp. 368.

Soniewicki, M., and Paliszkiewicz, J., 2019. The importance of knowledge management processes for the creation of competitive advantage by companies of varying size. Entrepreneurial Business \& Economics Review, 7(3), pp. 43-63. https://doi.org/10.15678/EBER.2019.070303

Spiegler, I., 2000. Knowledge management: a new idea or a recycled concept? Communications of AIS, 3(14).

St-Amant, G. et Renard, L., 2004. Proposition d'un modèle de gestion du développement des capacités organisationnelles. XIle Conférence de l'Association Internationale de Management Stratégique (AIMS), Vallée de la Seine 2, 3 et 4 juin

Svieby, K. and Simons, R., 2002. Collaborative climate and effective knowledge of work: an empirical study. Journal of Knowledge Management, 6(5), pp. 420-433.

Venkatraman, N., 1994. IT-enabled business transformation: from automation to business scope redefinition. Sloan Management Review, Winter, pp. 73-87.

Weixu, D., Eugene, C., and Atsushi, A., 2019. Relational study of wise (phronetic) leadership, knowledge management capability, and innovation performance. Asia Pacific Management Review, 24(4), 310-317. https://doi.org/10.1016/j.apmrv.2018.10.005

Wernerfelt., B., 1984. A resource based view of the firm. Strategic Management Journal, 5(2), pp. 171-180.

Yin, R., 1994. Case study research: design and methods (2nd ed). Thousand Oaks, CA: Sage.

Zaied., A., 2012. An integrated knowledge management capabilities framework for assessing organization performance. International Journal of Information Technology and Computer Science. 2, pp. 1-10

https://doi:10.5815/ijitcs.2012.02.01 